\title{
Long-term Effects of the Angiotensin-converting Enzyme Inhibitor Enalapril on Chronic Heart Failure \\ Examination by ${ }^{123}$ I-MIBG Imaging
}

\author{
Takeshi Soeki, MD, Yoshiyuki Tamlra, MD, \\ Kanji Bandou, MD, Hideji TanaKa, MD, \\ Naoki Takeichi, MD, Hisanori ShInOHARA, MD, \\ Yasuko Yur, MD, Nobuo FukudA, ${ }^{1} \mathrm{MD}$, \\ and Osamu SuI, ${ }^{2} \mathrm{MD}$
}

\section{SUMMARY}

To examine the long-term effects of the angiotensin-converting enzyme (ACE) inhibitor enalapril on chronic heart failure, 10 patients ( 7 men and 3 women, mean age: $62 \pm 11$ years) with chronic stable heart failure, classified as New York Heart Association (NYHA) functional class 2-3 for more than 3 months, and a left ventricular ejection fraction less than $45 \%$ were treated with 2.5-5.0 mg of enalapril once a day for 3-15 months (mean 7 months). The causes of heart failure were old myocardial infarction $(n=7)$, hypertension $(n=2)$, and atrial fibrillation $(n=1)$. Radioiodinated metaiodobenzyl guanidine ( ${ }^{123} \mathrm{I}-\mathrm{MIBG)}$ imaging, radionuclide angiography, and treadmill exercise test were performed before and after the treatment. With enalapril treatment, (1) left ventricular ejection fraction (LVEF) increased significantly from $38.3 \pm 6.9 \%$ to $47.5 \pm 14.7 \%$; (2) sub-maximal exercise time increased significantly from $205 \pm 112$ to $272 \pm 120$ seconds; (3) the heart to mediastinum (H/ M) ratio of ${ }^{123} \mathrm{I}-\mathrm{MIBG}$ increased significantly (early image: $1.99 \pm 0.38$ versus $2.20 \pm 0.50$; delayed image: $1.86 \pm 0.44$ versus $2.09 \pm 0.51$ ); and (4) the washout rate of ${ }^{123} \mathrm{I}-\mathrm{MIBG}$ decreased slightly from $29.1 \pm 9.1 \%$ to $25.4 \pm 7.0 \%$. The improvement rate of LVEF was significantly correlated with the improvement rates of the $\mathrm{H} / \mathrm{M}$ ratio and washout rate after treatment with enalapril. Thus, the long-term effects of enalapril can be observed in the cardiac sympathetic nervous system, and ${ }^{123}$ I-MIBG imaging appears to be useful for evaluating the therapeutic effects of enalapril on the cardiac sympathetic nervous system in patients with chronic heart failure. (Jpn Heart J 1998; 39: 743-751)

Key words: Angiotensin-converting enzyme (ACE) inhibitor, Heart failure, Radioiodinated metaiodobenzyl guanidine ( ${ }^{123}$ I-MIBG) imaging, Left ventricular ejection fraction (LVEF)

From the Department of Cardiology, 'Institute for Clinical Research, and ${ }^{2}$ Department of Radiology, Zentsuji National Hospital, Zentsuji, Kagawa, Japan.

Address for correspondence: Takeshi Soeki, MD, Department of Cardiology, Zentsuji National Hospital, Senyu-cho 2-1-1, Zentsuji, Kagawa 765-8507, Japan.

Received for publication May 13, 1998.

Revised and accepted September 28, 1998. 
INCE angiotensin-converting enzyme (ACE) inhibitors are known to dilate $N$ both arteries and veins and to exert diuretic effects, these agents are generally used in patients with chronic heart failure. Recently, mega-trials have clearly shown that therapy with ACE inhibitors not only improves clinical symptoms and exercise tolerance but also reduces mortality. ${ }^{1-5)}$ Cardiac sympathetic nerve activity is clearly related to cardiac function, and radioiodinated metaiodobenzyl guanidine ( ${ }^{123}$ I-MIBG) imaging has been used to evaluate cardiac sympathetic nerve activity. ${ }^{6}$ In fact, it has been reported that the heart-to-mediastinum $(\mathbf{H} /$ M) activity rate of MIBG is decreased and the myocardial washout rate of MIBG is increased in patients with chronic heart failure, and that these parameters are useful in predicting their survival. ${ }^{7-9)}$ The objectives of the present study were: (1) to investigate the long-term effects of the ACE inhibitor, enalapril, in patients with chronic heart failure using ${ }^{123}$ I-MIBG imaging; and (2) to compare these results with other cardiac functional indexes.

\section{Methods}

Patients: The subjects were 10 patients $(7 \mathrm{men}, 3$ women, mean age: $62 \pm 11$ years) with chronic stable heart failure, classified as New York Heart Association (NYHA) functional class 2-3 for more than 3 months, and left ventricular ejection fraction of less than $45 \%$ (Table I). The causes of heart failure were old myocardial infarction $(n=7)$, hypertension $(n=2)$, and atrial fibrillation $(n=1)$. They were treated with $2.5-5.0 \mathrm{mg}$ of enalapril once a day for 3-15 months (mean: 7 months). The doses of other medications were not altered during the study.

Study protocol: The following tests and examinations were performed and the

Table I. Patient Characteristics

\begin{tabular}{rlllllllc}
\hline Pt No. & Case & $\begin{array}{c}\text { Age } \\
\text { (yrs) }\end{array}$ & Sex & Diagnosis & $\begin{array}{c}\text { NYHA } \\
\text { class }\end{array}$ & $\begin{array}{c}\text { Drugs in } \\
\text { combination }\end{array}$ & $\begin{array}{c}\text { Dose of } \\
\text { enalapril } \\
\text { (mg/day) }\end{array}$ & $\begin{array}{c}\text { Treatment } \\
\text { period } \\
\text { (months) }\end{array}$ \\
\hline I & Y.O & 65 & F & OMII & II & N & 2.5 & 7 \\
2 & Z.I & 60 & M & OMI & III & N & 2.5 & 5 \\
3 & T.Y & 76 & M & OMI & III & N, C & 2.5 & 4 \\
4 & E.H & 48 & F & Af & II & Du, Dg & 2.5 & 10 \\
5 & K.S & 48 & M & OMI & III & N, C & 2.5 & 15 \\
6 & T.U & 70 & M & OMI & II & N & 2.5 & 5 \\
7 & K.K & 78 & M & OMI & II & N, C & 2.5 & 6 \\
8 & M.O & 69 & M & OMI & II & N, C & 5.0 & 3 \\
9 & T.T & 60 & M & HHD & III & Du & 2.5 & 4 \\
10 & M.M & 50 & F & HHD & III & Du, C & 5.0 & 10 \\
\hline
\end{tabular}

$\mathrm{OMI}=$ old myocardial infarction; $\mathrm{Af}=$ atrial fibrillation; $\mathrm{HHD}=$ hypertensive heart disease; $\mathrm{N}=\mathrm{Nitrates}$; $\mathrm{C}=\mathrm{Ca}$ antagonists; $\mathrm{Du}=$ diuretics; $\mathrm{Dg}=$ digitalis. 
results obtained before and after enalapril treatment compared: NYHA class, blood pressure, cardiothoracic ratio on chest X-ray, left ventricular end-diastolic volume and ejection fraction on radionuclide angiography, exercise time by treadmill test, plasma hormonal values before and after exercise, and the $\mathrm{H} / \mathrm{M}$ ratio and myocardial washout rate by ${ }^{123}$ I-MIBG imaging.

Radionuclide angiography: After a bolus injection of $20-25 \mathrm{mCi}$ of ${ }^{99 \mathrm{~m}} \mathrm{Tc}-$ pertechnetate in approximately $0.1 \mathrm{cc}$ followed by a large-volume (approximately $20 \mathrm{cc}$ ) saline flush, planar gated blood-pool scintigraphy was obtained in the best septal LAO projection for 700 beats with low-energy high-resolution parallelhole collimators, $128 \times 128$ matrix, 16 time frame ECG gating, and a 15\% R-R interval acceptance window. Left ventricular end-diastolic volume and ejection fraction were calculated semiautomatically with commercially available software (TOSHIBA NEW GMS-550U, TOSHIBA Medical Co., Ltd., Tokyo).

Exercise test and blood sampling: Exercise tolerance was evaluated by treadmill test, and the time to sub-maximal exercise was measured using the modified method of Bruce. The target heart rate was calculated as follows: target heart rate $=(220$-age $) \times 0.95$. The end points without a target heart rate were exhaustion, anginal pain, or myocardial ischemia on the electrocardiogram (Eight of 10 patients accomplished the target heart rate before treatment, and 9 patients after treatment). Blood samples were drawn via an intravenous line inserted 30 minutes before sampling with the patient in the supine position for 30 minutes before exercise and drawn immediately after exercise, and plasma renin activity, plasma aldosterone, plasma noradrenaline, and plasma atrial natriuretic peptide were measured.

MIBG imaging: After 111 megabecquerel of MIBG were injected via an antecubital vein at rest and during fasting, planar studies in the anterior view were performed at $20 \mathrm{~min}$ and $4 \mathrm{hr}$. Recordings were made of regions of interest over the left ventricular myocardium and upper mediastinum areas, and the $\mathrm{H}$ / $\mathrm{M}$ ratio was calculated to quantify cardiac ${ }^{123}$ I-MIBG uptake as the average count per pixel in the left ventricular myocardium divided by the average count per pixel in the upper mediastinum. The washout rate of ${ }^{123}$ I-MIBG from the myocardium was calculated from the absolute counts in early and delayed images.

Statistical analysis: Data are expressed as mean \pm SD. Student's $t$ test for paired data was used, and a probability of $p<0.05$ was considered significant. Correlations are expressed by the Pearson correlation coefficient.

\section{Results}

Changes in NYHA class, blood pressure, and cardio-thoracic ratio: The 
Table II. Clinical, Scintigraphic, and Hormonal Variables

\begin{tabular}{lccc}
\hline & Baseline & After treatment & $p$ value \\
\hline Blood pressure (mmHg) & $142 \pm 24$ & $137 \pm 17$ & NS \\
Cardio- thoracic ratio (\%) & $54.9 \pm 9.5$ & $51.9 \pm 8.8$ & NS \\
Exercise time (seconds) & $205 \pm 112$ & $272 \pm 120$ & $<0.05$ \\
Radionuclide angiography & & & \\
LVEF $\%$ ) & $35 \pm 9$ & $45 \pm 14$ & $<0.05$ \\
LVEDV (m) & $154 \pm 30$ & $146 \pm 31$ & NS \\
${ }^{123}$ l-MIBG imaging & & & \\
H/M ratio (early image) & $1.99 \pm 0.38$ & $2.20 \pm 0.50$ & $<0.05$ \\
H/M ratio (delayed image) & $1.86 \pm 0.44$ & $2.09 \pm 0.51$ & $<0.05$ \\
Washout rate (\%) & $29.1 \pm 9.1$ & $25.4 \pm 0.7$ & NS \\
Hormonal values & & & \\
Noradrenaline (ng/m) & $0.528 \pm 0.265$ & $0.734 \pm 0.320$ & $<0.05$ \\
Noradrenaline (ratios of values before vs after exercise) & $2.82 \pm 1.18$ & $2.42 \pm 1.05$ & NS \\
Aldsterone (pg/m) & $65.2 \pm 31.5$ & $64.7 \pm 62.4$ & NS \\
Aldsterone (ratios of values before vs after exercise) & $1.19 \pm 0.23$ & $1.24 \pm 0.31$ & NS \\
PRA (ng/ml/hr) & $2.19 \pm 1.55$ & $19.88 \pm 24.61$ & $<0.05$ \\
PRA (ratios of values before vs after exercise) & $1.46 \pm 0.43$ & $1.32 \pm 0.43$ & NS \\
ANP (pg/m) & $32.5 \pm 21.3$ & $24.1 \pm 13.9$ & $<0.05$ \\
ANP (ratios of values before vs after exercise) & $1.46 \pm 0.43$ & $1.60 \pm 0.57$ & NS \\
\hline
\end{tabular}

LVEF = left ventricular ejection fraction; $L V E D V=$ left ventricular end-diastolic volume; $\mathrm{H} / \mathrm{M}$ ratio $=$ heart to mediastinum ratio; $\mathrm{PRA}=$ plasma renin activity; $\mathrm{ANP}=$ atrial natriuretic peptide .

NYHA class improved in 3 of 10 patients (2 patients: from class 3 to class 2; 1 patient: from class 2 to class 1) after enalapril therapy. Clinical, scintigraphic, and hormonal values before and after treatment are shown in Table II. Systolic blood pressure and the cardio-thoracic ratio showed slight decreases after treatment compared with the baseline values.

Changes in left ventricular ejection fraction and end-diastolic volume: Left ventricular ejection fraction on radionuclide angiography improved significantly from $35 \pm 9$ to $45 \pm 14 \%$. Left ventricular end-diastolic volume on radionuclide angiography decreased slightly from $154 \pm 30$ to $146 \pm 31 \mathrm{ml}$ (NS).

Changes in exercise time: Submaximal exercise time on the treadmill exercise test was extended significantly from $205 \pm 112$ to $272 \pm 120$ seconds after treatment.

Changes in hormonal values: Plasma renin activity and noradrenaline increased significantly, and plasma atrial natriuretic peptide decreased significantly after treatment. However, the ratios of plasma renin activity, noradrenaline, and atrial natriuretic peptide values before versus after exercise did not change significantly.

Changes in ${ }^{123}$ I-MIBG myocardial imaging: The H/M ratio in the early and delayed images increased significantly from $1.99 \pm 0.38$ and $1.86 \pm 0.44 \%$ to $2.20 \pm 0.50$ and $2.09 \pm 0.51 \%$, respectively. The myocardial washout rate decreased slightly, but not significantly, from $29.1 \pm 9.1$ to $25.4 \pm 7.0 \%$. 
(\%) \%change in LVEF

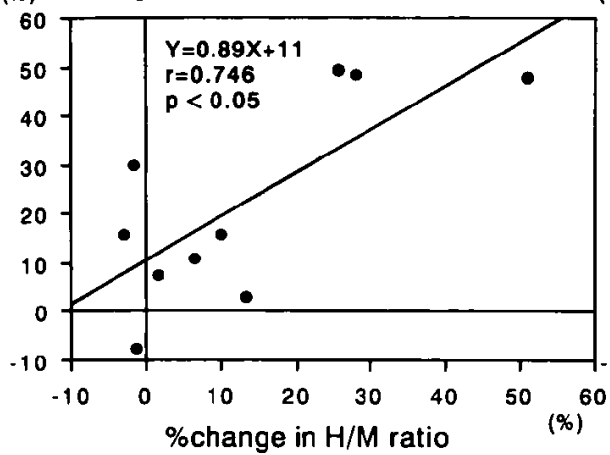

(\%) \%change in LVEF

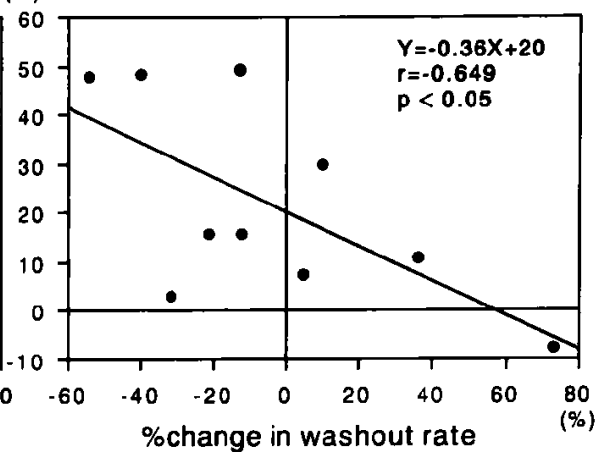

Figure. Relationships between the improvement rates of $\mathrm{LVEF}$ and the $\mathrm{H} / \mathrm{M}$ ratio and between LVEF and the washout rate. \%Change was calculated as an indicator of the improvement rate for each parameter according to the following equation: $\%$ change in $\mathrm{X}=[$ (posttreatment value of $\mathrm{X}$-pretreatment value of $\mathrm{X} /$ pretreatment value of $\mathrm{X}] \times 100 . \mathrm{H} / \mathrm{M}$ ratio $=$ heart-to-mediastinum ratio; $\mathrm{LVEF}=$ left ventricular ejection fraction.

Relationship between the improvement rates for left ventricular ejection fraction and the $H / M$ ratio and between those of left ventricular ejection fraction and washout rate: The Figure shows the relationships between the improvement rates for left ventricular ejection fraction and the $H / M$ ratio and between the improvement rates for left ventricular ejection fraction and washout rate. The improvement rate for each parameter was calculated as \%change according to the following equation: \%change in $\mathrm{X}=[$ (posttreatment value of $\mathrm{X}$ - pretreatment value of $\mathrm{X}) /$ pretreatment value of $\mathrm{X}] \times 100$. A significantly positive correlation $(r=0.746, p<0.05)$ was found between the \%change in the left ventricular ejection fraction and the $\mathrm{H} / \mathrm{M}$ ratio, while a significantly negative correlation $(r=-0.649, p<0.05)$ was seen between the \%change in left ventricular ejection fraction and the washout rate. However, the correlations between the $\%$ change in submaximal exercise time and the $\mathrm{H} / \mathrm{M}$ ratio $(r=-0.525$, $p=0.1229)$ or the washout rate $(r=0.428, p=0.2260)$ were not significant.

\section{Discussion}

In this study, left ventricular ejection fraction determined by radionuclide angiography and exercise tolerance determined by treadmill test both improved significantly after long-term administration of enalapril (average 7 months). Plasma renin activity at rest increased significantly after enalapril treatment, which corresponds to the results of other reports. ${ }^{10-12)}$ Plasma noradrenaline at rest also increased significantly after treatment. However, because noradrenaline 
was only increased by less than 1.5-fold and atrial natriuretic peptide decreased at the same time, the rise in noradrenaline may not necessarily represent a deterioration in cardiac function. McGrath reported that the plasma noradrenaline response to graded exercise in patients with heart failure was significantly reduced after 4 weeks of enalapril treatment. ${ }^{14)}$ In this study, plasma noradrenaline after exercise and the ratio of noradrenaline values before to those after exercise were not significantly altered by enalapril treatment. It has been reported that ACE inhibitors reduce plasma noradrenaline concentrations in patients with moderate heart failure to a lesser extent than in those with severe heart failure. ${ }^{1,13 !}$ Our results might reflect the fact that patients with moderate heart failure predominated in this study. However, these results may have been caused by the small number of patients studied or mental stress during the preexercise blood sampling.

The uptake mechanism (uptake-1) for ${ }^{123}$ I- MIBG, a guanethidine ana$\operatorname{logue} e^{6)}$, in the sympathetic nerve endings is similar to that of noradrenaline ${ }^{(5)}$ and the compound is stored in the noradrenaline storage granules. ${ }^{16)}$ MIBG myocardial imaging, which utilizes this mechanism, enables researchers to visually evaluate cardiac sympathetic nerve activity. ${ }^{17)}$ It has been reported that MIBG accumulation, reflected in the $\mathrm{H} / \mathrm{M}$ ratio, is decreased and the myocardial washout rate is accelerated in patients with heart failure. ${ }^{7-9)}$ As in other reports, this study also showed an aberration in MIBG myocardial accumulation before treatment in patients with heart failure. Since 7 of our 10 patients had previous myocardial infarction, a decreased viable myocardial amount due to decreased coronary blood flow, aberrations in energy-dependent uptake-1, left ventricular expansion which increases the number of pixels in the myocardial regions of interest and decreases the myocardial count per pixel, and/or other factors may cause a decrease in the early $\mathrm{H} / \mathrm{M}$ ratio, and the facilitation of noradrenaline turnover and an aberration in the noradrenaline maintenance function of the sympathetic nerve endings might cause an increase in the washout rate.

Some reports have shown that MIBG myocardial imaging is useful for evaluating the effects of $\beta$-blocker therapy in patients with dilated cardiomyopathy. ${ }^{18,19)}$ However, only two studies have examined the effects of ACE inhibitors on cardiac MIBG imaging in patients with congestive heart failure. ${ }^{20,21)}$ Somsen et $a l .{ }^{20)}$ reported that enalapril seemed to improve cardiac sympathetic neuronal uptake function but did not significantly affect plasma noradrenaline concentrations in patients with heart failure (NYHA classes II-IV) after 6 weeks of treatment. Their study protocol differed from ours in that their treatment period was shorter and they evaluated MIBG uptake by single-photon emission computed tomography. Takeishi et al. ${ }^{21)}$ reported that the $\mathrm{H} / \mathrm{M}$ ratio and washout rate improved in patients with heart failure (NYHA classes II-III) 
after enalapril treatment for 9 months, and left ventricular ejection fraction increased in patients with a raised $\mathrm{H} / \mathrm{M}$ ratio after treatment. Their study differed from ours in that dilated cardiomyopathy was the most common cause of heart failure (about $45 \%$ ) in their patient group. Also, since the dose of enalapril in our study (2.5-5.0 mg/day) was different from those used in these two reports (5-20 and 5-10 mg/day, respectively), our results suggest that a low dose of enalapril also improves cardiac sympathetic nerve function.

Although Takeishi et al. ${ }^{21}$ demonstrated that the washout rate as well as the $\mathrm{H} / \mathrm{M}$ ratio improved significantly after treatment, our results showed that both the early and delayed $\mathrm{H} / \mathrm{M}$ ratios improved significantly, while the washout rate improved only slightly after enalapril treatment. This difference may reflect the inclusion of 7 patients with old myocardial infarction out of the 10 subjects in our study. This might be caused by an improvement in the sympathetic nerve function in the non-infarcted areas, and an improvement in uptake- 1 might have a large influence on this finding due to the increased early $\mathrm{H} / \mathrm{M}$ ratio. Although it has been shown that myocardial sympathetic reinnervation in denervated, infarcted, and transplanted hearts can be detected by MIBG imaging, ${ }^{22-24}$ reinnervation in the infarcted area is unlikely to occur for several months in the chronic stage of disease. Even though an improvement in cardiac dilatation might have led to the increased $\mathrm{H} / \mathrm{M}$ ratios observed in the early and delayed phases, neither the cardio-thoracic ratio nor left ventricular end-diastolic volume determined by radionuclide angiography changed significantly after treatment in the present study, indicating that cardiac dilatation did not improve.

Based on the above findings, the improvement in sympathetic nerve function with ACE inhibitor therapy may result from the improved efficiency of uptake-1, as indicated by an improved early $\mathrm{H} / \mathrm{M}$ ratio, or by a decrease in MIBG release at the sympathetic nerve endings, represented by the slight improvement in the washout rate. Whether ACE inhibition improves the efficiency of uptake-1 or decreases MIBG release is unknown, and this most likely varies according to the cause of the heart failure. Furthermore, the improvement in hemodynamics due to vasodilation induced by an ACE inhibitor may indirectly result in improved sympathetic nerve function, but the present data do not support this since blood pressure did not change significantly after treatment in our study. The absence of a change in blood pressure in the present study may reflect the use of low doses (2.5-5.0 mg/day) of enalapril.

With respect to the relationship between cardiac function and ${ }^{123} \mathrm{I}-\mathrm{MIBG}$ myocardial imaging, the improvement rate of the left ventricular ejection fraction was significantly correlated with the improvement of the $\mathrm{H} / \mathrm{M}$ ratio and the washout rate after treatment with enalapril. These results suggest that ${ }^{123}$ I-MIBG myocardial imaging may be useful for monitoring the effects of ACE inhibitor 
therapy on heart failure. However, the correlations between the \%changes in submaximal exercise time and the $\mathrm{H} / \mathrm{M}$ ratio or washout rate were not significant. These results may reflect the fact that some patients failed to accomplish the target heart rate.

In conclusion, ${ }^{123}$ I-MIBG might be useful for evaluating the therapeutic effects of enalapril on the cardiac sympathetic nervous system in patients with chronic heart failure.

\section{REFERENCES}

1. The CONSENSUS Trial Study Group. Effect of enalapril on mortality in congestive heart failure. $\mathrm{N}$ Engl J Med 1987; 316: 1429-35.

2. The SOLVD Investigators. Effects of the angiotensin converting enzyme inhibitor enalapril on survival in patients with reduced left ventricular ejection fractions and congestive heart failure. $\mathrm{N}$ Engl $\mathrm{J}$ Ned 1991; 325: 293-302.

3. The SOLVD Investigators. Effects of enalapril on mortality and the development of heart failure in asymptomatic patients with reduced left ventricular ejection. $\Lambda^{x}$ Engl J Med 1992; 327: 685-91.

4. Cohn JN, Johnson G, Ziesche S, et al. A comparison of enalapril with hydralazine-isosorbide dinitrate in the treatment of chronic congestive heart failure. $\mathcal{N}$ Engl J Med 1991; 325: 303-10.

5. The SAVE Investigators. Effect of captopril on mortality and morbidity in patients with left ventricular dysfunction after myocardial infarction. N Engl J Med 1992; 327: 669-77.

6. Wieland DM. Wu JL, Brown LE, Mangner TJ, Swanson DP, Beierwaltes WH. Radiolabeled adrenergic neuron-blocking agents: Adrenomedullary imaging with [131П iodobenzylguanidine. J Nucl Med 1980; 33: 349-53.

7. Henderson EB, Kahn JK, Corbett JR, et al. Abnormal I-123 metaiodobenzylguanidine myocardial washout and distribution may reflect myocardial adrenergic derangement in patients with congestive cardiomyopathy. Circulation 1988; 78: 1192-9.

8. Schofer J, Spielmann R, Schuchert A, Weber K, Schluter M. Iodine-123 metaiodobenzylguanidine scintigraphy: a noninvasive method to demonstrate myocardial adrenergic nervous system disintegrity in patients with idiopathic dilated cardiomyopathy. J Am Coll Cardiol 1988; 12: 1252-8.

9. Merlet P, Valette H, Dubois-Rande JL, et al. Prognostic value of cardiac metaiodobenzylguanidine imaging in patients with heart failure. J Nucl Med 1992; 33, 471-7.

10. Cody RJ. Clinical and hemodynamic experience with enalapril in congestive heart failure. Am $\mathbf{J}$ Cardiol 1985; 55, 36-40.

11. Levine TB, Olivari MT, Garberg V, Sharkey SW, Cohn JN. Hemodynamic and clinical response to enalapril, a long-acting converting enzyme inhibitor, in patients with congestive heart failure. Circulation 1984; 69, 548-53.

12. Cleland JG, Dargie HJ, Ball SG, et al. Effects of enalapril in heart failure: a double blind study of effects on exercise performance, renal function, hormones, and metabolic state. Br Heart J 1985; 54, 305-12.

13. Swedberg K, Eneroth P, Kjekshus J, Wilhelmsen L. Hormones regulating cardiovascular function in patients with severe congestive heart failure and their relation to mortality. Circulation $1990 ; 82,1730-$ 6.

14. McGrath BP, Arnolda LF. Enalapril reduces the catecholamine response to exercise in patients with heart failure. Eur J Clin Pharmacol 1986; 30, 485-7.

15. Tobes MC, Jacques S Jr, Wieland DM, Sisson JC. Effect of uptake-one inhibitors on the uptake of norepinephrine and metaiodobenzylguanidine. J Nucl Med .1985; 26, 897-907.

16. Wieland DM, Brown LE, Rogers WL, et al. Myocardial imaging with a radioiodinated norepinephrine storage analog. J Nucl Med 1981; 22, 22-31.

17. Sisson JC, Wieland DM, Sherman P, Mangner TJ, Tobes MC, Jacques SJr. Metaiodobenzylguanidine 
as an index of the adrenergic nervous system integrity and function. $\mathrm{J}$ Nucl Med 1987; 28, 1620-4.

18. Yamazaki J, Hosoi $\mathrm{H}$, Yamashina $\mathrm{H}$, et al. Clinical meaning of ${ }^{123}$ I-MIBG myocardial SPECT in patients with dilated cardiomyopathy. Kaku Igaku 1994; 31, 373-7.

19. Wakita $T$, Numata $Y$, Ogata $Y$, Harada E, Mizumasa $Y$. The relationship between the improvement of cardiac function and the myocardial uptake of I- 123 metaiodobenzylguanidine in patients with dilated cardiomyopathy treated by beta-blocker. J Cardiol 1995; 26, 177-83.

20. Somsen GA, van Vlies B, de Milliano PA, et al. Increased myocardial [123I]-metaiodobenzylguanidine uptake after enalapril treatment in patients with chronic heart failure. Heart 1996; 76, 218-22.

21. Takeishi Y, Atsumi H, Fujiwara S, Takahashi K, Tomoike H. ACE inhibition reduces cardiac Iodine123-MIBG release in heart failure. J Nucl Med 1997; 38, 1085-9.

22. Minardo JD, Tuli MM, Mock BH, et al. Scintigraphic and electrophysiological evidence of canine myocardial sympathetic denervation and reinnervation produced by myocardial infarction on phenol application. Circulation 1988; 78, 1008-19.

23. Nishimura $\mathrm{T}$, Oka $\mathrm{H}$, Sago M, et al. Serial assessment of denervated but viable myocardium following acute myocardial infarction in dogs using iodine- 123 metaiodobenzylguanidine and thallium-201 chloride myocardial single photon emission tomography. Eur J Nucl Med 1992; 19, 25-9.

24. Glowniak JV, Turner FE, Gray LL, Palac RT, Lagunas-Solar MC, Woodward WR. Iodine-123 metaiodobenzylguanidine imaging of the heart in idiopathic congestive cardiomyopathy and cardiac transplants. J Nucl Med 1989; 30, 1182-91. 